\title{
Review of risk factors for human echinococcosis prevalence on the Qinghai-Tibet Plateau, China: a prospective for control options
}

Qian Wang ${ }^{1 *}$, Yan Huang ${ }^{1}$, Liang Huang ${ }^{1}$, Wenjie Yu' ${ }^{1}$, Wei He ${ }^{1}$, Bo Zhong ${ }^{1 *}$, Wei $\mathrm{Li}^{2^{*}}$, Xiangman Zeng ${ }^{3}$, Dominique A Vuitton ${ }^{4}$, Patrick Giraudoux ${ }^{5}$, Philip S Craig ${ }^{6}$ and Weiping $\mathrm{Wu}^{3^{*}}$

\begin{abstract}
Objective: Echinococcosis is a major parasitic zoonosis of public health importance in western China. In 2004, the Chinese Ministry of Health estimated that 380,000 people had the disease in the region. The Qinghai-Tibet Plateau is highly co-endemic with both alveolar echinococcosis (AE) and cystic echinococcosis (CE). In the past years, the Chinese government has been increasing the financial support to control the diseases in this region. Therefore, it is very important to identify the significant risk factors of the diseases by reviewing studies done in the region in the past decade to help policymakers design appropriate control strategies.

Review: Selection criteria for which literature to review were firstly defined. Medline, CNKI (China National Knowledge Infrastructure), and Google Scholar were systematically searched for literature published between January 2000 and July 2011. Significant risk factors found by single factor and/or multiple factors analysis were listed, counted, and summarized. Literature was examined to check the comparability of the data; age and sex specific prevalence with same data structures were merged and used for further analysis.

A variety of assumed social, economical, behavioral, and ecological risk factors were studied on the Plateau. Those most at risk were Tibetan herdsmen, the old and female in particular. By analyzing merged comparable data, it was found that females had a significant higher prevalence, and a positive linearity relationship existed between echinococcosis prevalence and increasing age. In terms of behavioral risk factors, playing with dogs was mostly correlated with CE and/or AE prevalence. In terms of hygiene, employing ground water as the drinking water source was significantly correlated with CE and AE prevalence. For definitive hosts, dog related factors were most frequently identified with prevalence of $C E$ or/and $A E$; fox was a potential risk factor for $A E$ prevalence only. Overgrazing and deforestation were significant for AE prevalence only.

(Continued on next page)
\end{abstract}

\footnotetext{
*Correspondence: wangqian1967@163.com; zhongbo1968@163.com; liwei51101@aliyun.com; wuweiping@hotmail.com

${ }^{1}$ Sichuan Provincial Center for Diseases Control and Prevention, Chengdu, Sichuan, China

${ }^{2}$ Ganzi Prefecture Center for Diseases Control and Prevention, Kangding, Sichuan, China

${ }^{3}$ Institute of Parasitic Diseases, China Center for Diseases Control and

Prevention, Shanghai, China

Full list of author information is available at the end of the article
} 


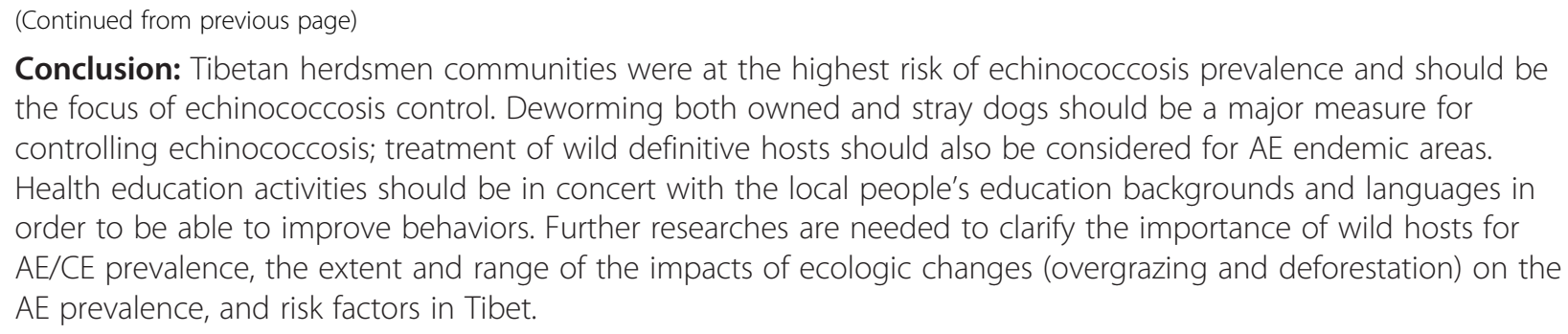

Keywords: Echinococcosis, Risk factors, Qinghai-Tibet Plateau, Control options

\section{Multilingual abstract}

Please see Additional file 1 for translations of the abstract into the six official working languages of the United Nations.

\section{Background}

Human cystic echinococcosis (CE) and alveolar echinococcosis (AE) are caused by the larval stage of E. granulosus and E. multilocularis, respectively. Transmission of $\mathrm{CE}$ and $\mathrm{AE}$ to humans is by unintentional consumption of parasite eggs excreted in the feces of the definitive hosts such as dogs and foxes. Geographically, CE has a universal distribution, while $\mathrm{AE}$ is confined to the northern hemisphere. In humans, infection results in a metacestode in the liver mostly. Chemotherapy is required continuously for many years, or even for the entire lifetime. In the absence of treatment, the disease is fatal. $\mathrm{AE}$ mortality could reach $94 \%$ and above if untreated within 10 years [1,2]. It has been acknowledged as one of the world's most lethal parasitic zoonoses [3].

The World Health Organization (WHO) listed echinococcosis, including both $\mathrm{CE}$ and $\mathrm{AE}$, as a neglected tropical disease in 2010 [4]. The estimated worldwide human burden of CE is 285,407 (95\% confidence interval [CI], 218,515-366,133) DALYs [5], and the figure for AE is 666,434 DALYs (CIs 331,000-1.3 million) [6]. China is responsible for $40 \%$ of the global CE DALYs [5] and 91\% of global AE DALYs [6]. In western China, 380,000 patients were estimated by a nationwide sampling survey conducted from 2001 to 2004 [7]. The figure indicates that western China is a highly-endemic area of echinococcosis worldwide. The survey estimated that the prevalences of echinococcosis in Tibet, Tibetan communities in Sichuan, and Qinghai Province were 2.76\%, 2.33\%, and $1.91 \%$, respectively. These figures were the top three in the nation, and indicated Qinghai-Tibet Plateau to be the most endemic area in China (see Figure 1).

The Qinghai-Tibet Plateau is located at $26^{\circ} 00^{\prime} 12^{\prime \prime} \mathrm{N} \sim$ $39^{\circ} 46^{\prime} 50^{\prime \prime} \mathrm{N}$ and $73^{\circ} 18^{\prime} 52^{\prime \prime} \mathrm{E} \sim 104^{\circ} 46^{\prime} 59^{\prime \prime} \mathrm{E}$ in western China. It covers most of the Tibet Autonomous Region and the Qinghai Province, as well as part of the Sichuan Province, the Gansu Province, the Xinjiang Uygur Autonomous Region, and the Yunnan Province. A part of the Plateau is bordered to the south by the Himalayan range, to the north by the Kunlun range, to the northeast by the Qilian range, to the east by the Hengduan Mountains, and to the west by the Pamir Mountains. There are some 155 counties/cities located in the Plateau, and some 61 counties/cities at the edge of the Plateau. The estimated population was 1,204 million [8].

Two forms of echinococcosis, $\mathrm{CE}$ and $\mathrm{AE}$, are highly endemic on the Qinghai-Tibet Plateau [7]. The domestic lifecycle and sylvatic lifecycle were assumed for E. granulosus and E. multilocularis [9] respectively, and indicated that the risk factors could be very complicated and diversified. To curb the transmission of the disease, the Chinese government is increasing the financial support for the control of echinococcosis. The resources allocation will largely depend on the control options decided on by keeping the significant risk factors in mind. Therefore, it is high time to review and identify the risk factors for echinococcosis on the Qinghai-Tibet Plateau, where the transmission $\mathrm{AE}$ and/or $\mathrm{CE}$ is very dynamic $[7,10-13]$. The findings could help policymakers design more targeted control strategies.

\section{Review \\ Methods \\ Selection criteria}

Literature with the following characteristics was included: 1. Diagnosis of human echinococcosis for communitybased studies was based on positive findings by abdominal ultrasound examinations and complemented by confirmatory serological tests, as WHO suggested [14]; diagnosis for hospital-based studies were dependent on abdominal ultrasounds, X-rays, computed tomography examinations, and complemented by confirmatory serological tests. 2 . Risk factors were linked to human prevalence. 3. Literature had to refer to an actual study rather than be a review of a study/studies. 


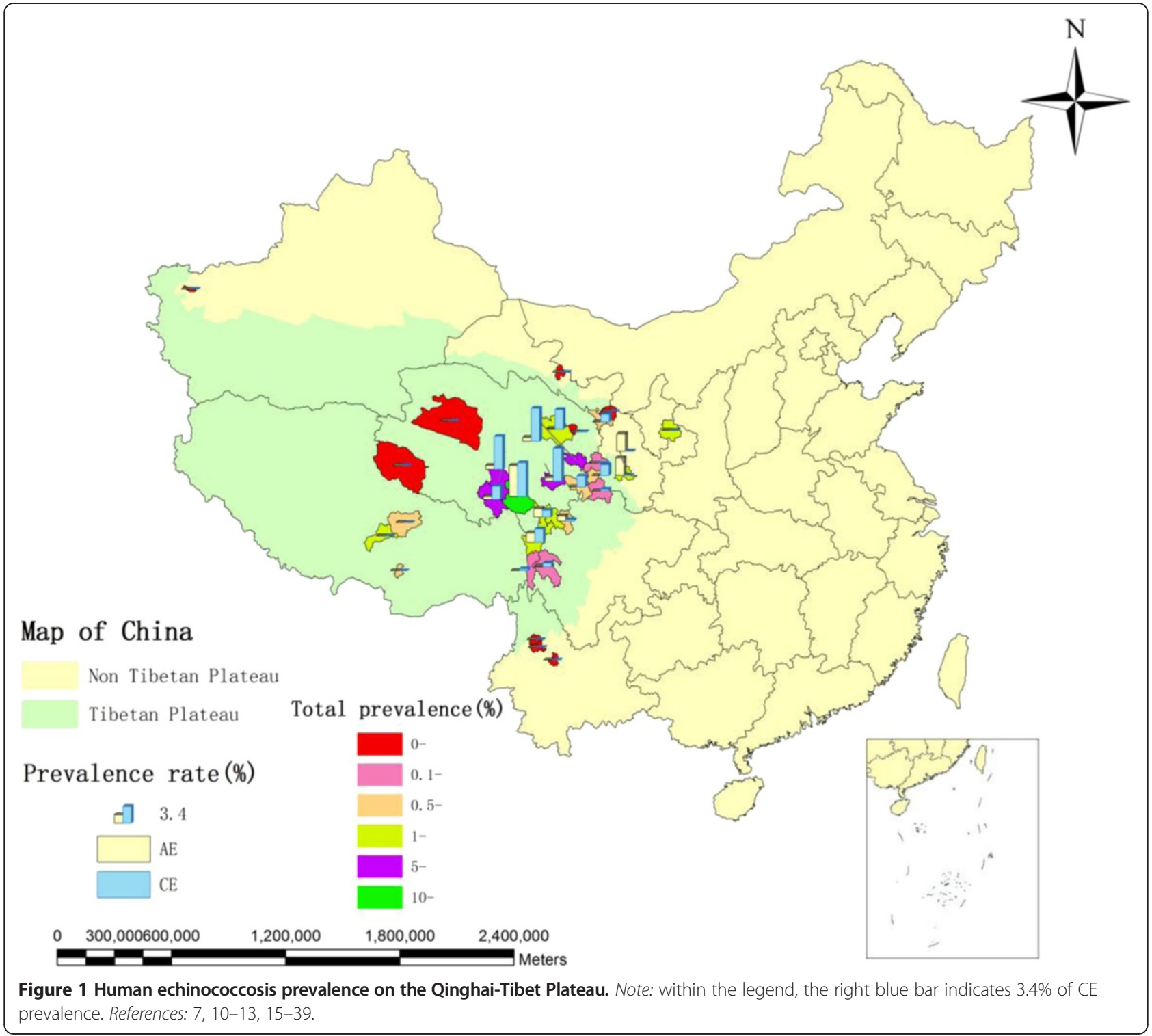

\section{Search strategy}

Medline, CNKI, and Google Scholar were searched for literature which was published between January 2000 and July 2011. Search terms included one word and/or phrase from each of following three categories: the name of the disease, including hydatidosis, hydatid disease, echinococcosis, and echinococcus; risk factors, including social, economy, religion, risk, behaviors, income, hygiene, and Buddhism; location, including Tibet, Qinghai, Qinghai-Tibet Plateau, Tibet Plateau, western China, Sichuan, Gansu, Yunnan, and Xinjiang. The languages of the literature were restricted to Chinese and English. Figure 2 shows a visualized strategy for the literature retrieval.

\section{Data analysis}

Significant risk factors found by single factor and/or multiple factors analysis were listed, counted, and summarized. The significant level of risk factors was $\mathrm{P}<0.05$ for both single factor and multiple factors analyses. Age specific prevalence with the same age span in each age group was merged from the data found in the literature. With the merged data, a trend figure of age specified prevalence was produced by Excel; an R-squared value was calculated and the linearity of the trend was tested. Sex specific data from the literatures were merged; Chisquare was used to compare the merged prevalence between males and females; 95\% confidence intervals were calculated for the sex specific prevalence. 


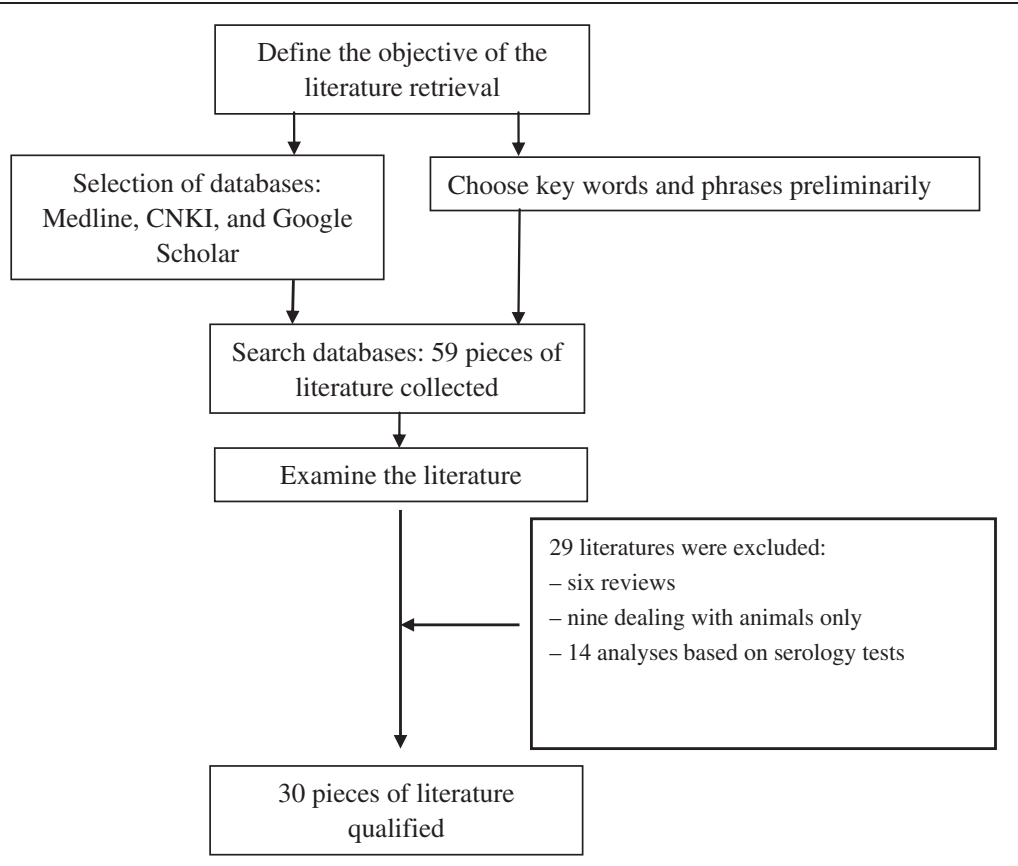

Figure 2 Strategy for literature retrieval.

\section{Results}

In total, 30 studies were found to address risk factors related to echinococcosis prevalence on the Qinghai-Tibet Plateau in the past decade [7,10-13,15-39]. Of those, ten, four, twelve, three, seven, and one were carried out in Qinghai, Tibet, Sichuan, Yunnan, Gansu, and Xinjiang, respectively (some studies covered several provinces/regions). The studies for human prevalence were communitybased except for two case studies conducted in Tibet, which were hospital based [15,32]. The participants of the community-based studies were all self-selected. Eight studies analyzed the risk factors for CE prevalence [15,16,23-26,32], 13 studied risk factors for AE prevalence [10,13,16,17,20,21,23,25,26,34-37], and 13 analyzed the risk factors for both $\mathrm{AE}$ and $\mathrm{CE}$ [7,11,12,18,19,23,25,27-30,38,39].

The studied risk factors were demographics, lifestyle, hygiene practices, drinking water source, slaughter and viscera disposal practices, animal ownership and dog related practices, small mammal indices, and land use practices (see Table 1).

For $\mathrm{CE}$ and/or $\mathrm{AE}$ together, increasing age $[7,11,12$, $15,16,18,20-23,25-27,30,31,36,38,39]$, being a female [7, $11,12,20-23,25-27,30,36,38,39]$, and coming from a herding population $[12,15,19,23,25-27,30,32,36,38]$ were the most significant demographic risk factors. In terms of behavioral factors, dog related factors were mostly correlated with $\mathrm{CE}$ and/or $\mathrm{AE}$ prevalence [10,12,16,20,21, $23,31,36]$. Longer periods of dog ownership [31] and stray dogs [23] were significant for CE prevalence only. In terms of hygiene, employing ground water as the drinking water source $[12,23,31,36]$ was significantly correlated with $\mathrm{CE}$ and/or AE prevalence [36]. Overgrazing $[13,26,35,37]$ and deforestation $[10,17]$ were significant for AE prevalence only.

Only one study [12] applied multiple factors analysis to identify risk factors for echinococcosis prevalence; the analysis included risk factors in the categories of demographics, lifestyle, slaughter and viscera related practices, animal ownership and dog related practices, water source, and hygiene practices. It found that increasing age, being a female, yak and/or sheep ownership, and allowing dogs to sleep indoors at night to be significant risk factors. For CE prevalence, two studies $[16,26]$ applied multiple stepwise logistic regression. One analysis [16] included risk factors of demographics, lifestyle, slaughter and viscera related practices, animal ownership and dog-related practices, water source, and hygiene practices. It found increasing age, yak and/or sheep ownership, and playing with dogs to be significant risk factors. Another study [26] included age, sex, and the area of fenced pasture into a multiple stepwise logistic regression, and identified increasing age to be significant. To identify risk factors for AE prevalence, three studies $[16,26,36]$ applied multiple stepwise logistic regressions, which included age, sex, and other factors. Increasing age was identified by three studies $[16,26,36]$; playing with dogs was found by two studies $[16,36]$; and factors identified by one study included being a female [36], yak and/or sheep ownership [16], fox skin products ownership [36], ground water as the drinking water source [36], overgrazing [26], and no protection of food from flies [36]. The significance of overgrazing was 
Table 1 Risk factors for human echinococcosis prevalence on the Qinghai-Tibet Plateau

\begin{tabular}{llcl}
\hline Risk factors & $\begin{array}{c}\text { Number of studies which found the factor being significant } \\
\text { by single factor analysis and references }\end{array}$ & References and locations of studies \\
\cline { 2 - 4 } Echinococcosis $\quad$ CE & AE
\end{tabular}

\section{Demographics}

Increasing age

$7\left(7,11,12^{*}, 27,30,38,39\right)$

Female

$9\left(7,11,12^{*}, 22,27,28,30,38,39\right)$

Herding population

$7\left(12^{*}, 19,25,27,30,32,38\right)$

Tibetan population

2(12,28)

Farming population

Nomadic

$2(12,27)$

Livestock ownership

Dog ownership

Total number of owned

dogs

Keeping two or more dogs

Longer period of dog

ownership

Stray dogs present

People's behaviors related to dogs

Playing with dogs

Leaving dogs untied

Allowing dogs to sleep indoors at night

Feeding dogs with viscera

Using dog feces as fertilizer

Fox skin products ownership

Hygiene-related behaviors

Ground water as a drinking water source

Never boiling water before consumption

Not washing hands before eating
$8(12,15$

$\left.16^{*}, 18,23,25,26^{*}, 31\right)$

1(23)

$6\left(16,20,21,23,25,36^{*}\right)$

$3(15,16,23)$

1(36)

1(36)

1(32)

$1(28)$

$1\left(12^{*}\right)$

1(12)

$1\left(12^{*}\right)$

$8\left(12,16^{*}, 20,21,23,25\right.$,
$\left.26^{*}, 36^{*}\right)$

7(Sichuan, Yunnan, Gansu, Qinghai, Xinjiang, Tibet), 11(Qinghai), 12(Qinghai), 15(Tibet), 16(Sichuan), 18(Qinghai), 20(Gansu), 21(Gansu), 23(Qinghai), 25(Qinghai), 26(Sichuan), 27(Sichuan), 30(Qinghai), 31(Gansu), 36(Sichuan), 38(Qinghai), 39(Sichuan)

7(Sichuan, Yunnan, Gansu, Qinghai, Xinjiang, Tibet), 11(Qinghai), 12(Qinghai),

16(Sichuan), 20(Gansu), 21 (Gansu),

22(Yunnan), 23(Qinghai), 25(Qinghai),

27(Sichuan), 28(Qinghai), 30(Qinghai),

36(Sichuan), 38(Qinghai), 39(Sichuan)

12(Qinghai), 15(Tibet), 16(Sichuan), 19(Gansu), 25(Qinghai), 23(Qinghai), 27(Sichuan), 30(Qinghai), 32(Tibet), 36(Sichuan), 38(Qinghai)

12(Qinghai), 28(Qinghai), 36(Sichuan)

20(Gansu), 21(Gansu), 32(Tibet) 28(Qinghai)

12(Qinghai), 16(Sichuan), 23(Qinghai) 12(Qinghai), 36(Sichuan)

12(Qinghai), 27(Sichuan), 23(Qinghai), 36(Sichuan)

$4\left(16^{*}, 20,21,36^{*}\right)$

$1\left(12^{*}\right)$

1(12)

$1(23)$

$2(23,31)$ $2\left(16^{*}, 36\right)$

$1(10)$

2(20,21)

$2(20,21)$

$2(20,21)$

$2\left(16,36^{*}\right)$

12(Qinghai), 16(Sichuan), 36(Sichuan)

23(Qinghai)

20(Gansu), 21 (Gansu)

31(Gansu)

23(Qinghai)

16(Sichuan), 20(Gansu), 21 (Gansu), 36(Sichuan)

20(Gansu), 21 (Gansu)

12(Qinghai)

12(Qinghai), 23(Qinghai)

20(Gansu), 21 (Gansu)

36(Sichuan)

12(Qinghai), 16(Sichuan), 23(Qinghai), 31(Gansu), 36(Sichuan)

12(Qinghai)

$2(23,36)$
10(Gansu) 
Table 1 Risk factors for human echinococcosis prevalence on the Qinghai-Tibet Plateau (Continued)

\begin{tabular}{|c|c|c|c|}
\hline $\begin{array}{l}\text { Not protecting food from } \\
\text { flies }\end{array}$ & $1(16)$ & $2\left(16,36^{*}\right)$ & 16(Sichuan), 36(Sichuan) \\
\hline \multicolumn{4}{|l|}{ Ecological factors } \\
\hline Density indices of voles & & $4(10,13,17,35)$ & $\begin{aligned} & \text { 10(Gansu), } \text { 13(Sichuan), 17(Gansu), } \\
& \text { 35(Sichuan) }\end{aligned}$ \\
\hline Deforestation & & $2(10,17)$ & 10(Gansu), 17(Gansu) \\
\hline Overgrazing & & $4\left(13,26^{*}, 35,37\right)$ & $\begin{array}{c}\text { 13(Sichuan), 26(Sichuan), 35(Sichuan), } \\
37 \text { (Sichuan, Qinghai) }\end{array}$ \\
\hline
\end{tabular}

Note: "*indicates that it was significant by multiple factors analysis also.

further supported by studies on the transmission of E. multilocularis $[35,40]$.

The significance of increasing age and being a female was further supported by analyzing merged comparable data from three studies $[7,11,29]$ conducted in Sichuan and the Qinghai Province. A strong trend of linearity was found between increased prevalence and increased age $\left(\mathrm{F}=124.9, \mathrm{P}=0.0001, \mathrm{R}^{2}=0.9615\right.$, sample size $\left.=23,785\right)$ (see Figure 3). By using a Chi-square test of merged data from two studies in Tibet [7], Sichuan Province [7], and Qinghai Province [7,11], it was found that female prevalence $(4.22 \%$, 95\% CI: 4.05-4.39\%, sample size $=13927)$ was significantly $\left(\chi^{2}=39.06, P<0.01\right)$ higher than that of male prevalence $(2.81 \%$, 95\% CI: $2.67-3.00 \%$, sample size $=13009$ ).

\section{Discussion and conclusion}

The reviewed studies [7,10-13,15-39] covered majority areas of the Qinghai-Tibet Plateau. However, most studies were done in Sichuan, Qinghai, and Gansu, while only three studies were done in Tibet $[7,15,32]$. Another important finding was that the studies were mostly done in highly-endemic areas with a prevalence of more than $1 \%$, except for three studies which were conducted in the Yunnan Province and one study in Xinjiang, where the prevalences were reported to be $0.03 \%$ and $0.19 \%$, respectively.

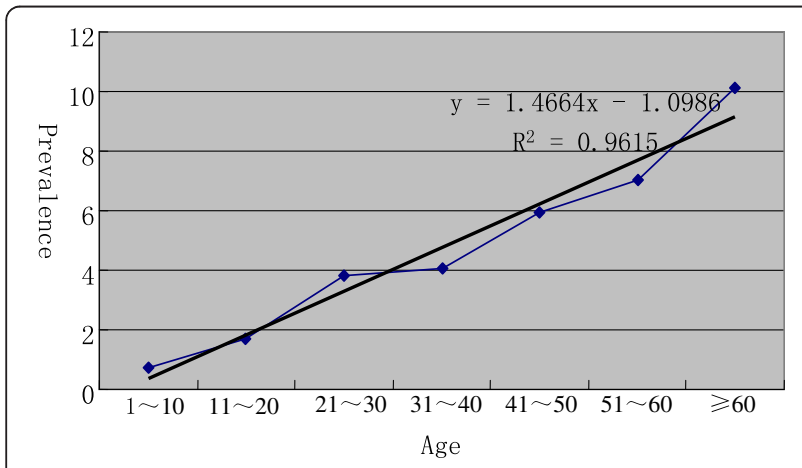

Figure 3 Trends of age specified prevalence of human echinococcosis on the Qinghai-Tibet Plateau. Notes: 1. Data source: 4,7 , and 24 . 2. Sample size was 23,785 . 3. Linearity test: $F=124.9, P=0.0001$.
The review identified that the Tibetan herdsman population, the old and females in particular, is at a significant higher risk of infliction by echinococcosis. Therefore, this population should be the focus of the control strategies. Dog- and fox-related risk factors for AE prevalence were studied carefully by several studies. Dog-related risk factors were found to be mostly significant $[10,20,21,23,26,31,36]$, while only one fox-related risk factor was found significant [36]; the factor was fox skin products ownership. On the Plateau, several studies found that both foxes and dogs (definitive hosts) [12,19,30,34,38,41] had a high prevalence of E. multilocularis. However, studies in Sichuan [26,27,36] and Gansu [20,21] could not find that the fox hunting population had a significant higher AE prevalence compared with other populations; no other studies tried to link foxes to AE prevalence statistically on the Plateau. These findings indicated that dogs may serve as a more important transmission source for human AE. This is a significant finding for $\mathrm{AE}$ prevalence. This finding is very different from the situation in Europe and Japan, where foxes were typically considered as a major transmission source of human AE $[10,42,43]$. Due to the significance of the fox skin products ownership, the role and the extent of foxes in the transmission of AE to humans should be the focus of future research.

Presence of stray dogs was significant for CE prevalence [23], but it may also have a role in advancing AE prevalence. A study found that the E. multilocularis prevalence in owned dogs was statistically associated with the number of stray dogs [40]. The killing of stray dogs is not possible due to local Buddhist beliefs that prohibits killing $[12,39]$. Therefore, the feasible control measures with priority on the Plateau should be treating both domestic and stray dogs with Praziquantel, dosing of foxes, and limiting dogs' access to infected viscera, when applicable. Key behaviors, such as not washing hands before eating and playing with dogs, should change. A health education strategy in concert with the population's education background and local languages is a must to effectively disseminate knowledge in order to help improve key behaviors.

E. granulosus, whose lifecycle is considered to be typically domestic [9], could possibly have a wild ungulate component on the Plateau; it was reported that wild 
ungulates died in large numbers due to cold and hunger in early spring [44]. Due to increasing protection by national laws and policies, the number of wild ungulates has been increasing consistently in recent years; for example, in Maduo county, Qinghai Province, the number of Tibetan gazelle, which live in the area between the altitude of 3,000 $\mathrm{m}$ to $5,000 \mathrm{~m}$, increased from 25,000 in 2000 to more than 40,000 in 2010. The number of Tibetan wild ass (Equus kiang) and blue sheep (Pseudois nayaur) had also increased drastically [45]. These animals are ungulates that are susceptive to E. granulosus [9]. The E. granulosus infection rate was reported to be $6.42 \%(21 / 327)$ for blue sheep and 6.57\% (13/198) for Tibetan gazelle in the Qinghai part of the Plateau [46]. Definitive hosts, including foxes and wolves, were found to be infected with E. granulosus [12,28,38]. A recent study indicated a possible contribution to the dogs' infection in early spring by dead wild ungulates in the Sichuan part of the Plateau [47]. Therefore, the role of wild hosts in the transmission of E. granulosus cannot be ignored, and further researches are needed.

Multiple factors regression is considered to be a far more accurate test than a single factor test; multiple factors regression returns results for the combined influence of all independent factors (variables) on the dependent factor, as well as the individual influence of each independent factor while controlling for the other independent factors [48]. The significant factors identified by multiple factors analyses were increasing age [12,26,36], being a female [12,36], herding population [12], yak and/or sheep ownership [12,16], allowing dogs to sleep indoors at night [12], playing with dogs $[16,36]$, fox skin products ownership [36], ground water as a drinking water source [36], overgrazing [26], and no protection of food from flies [36].

Overgrazing and deforestation were found to be significant for AE prevalence only; the former was studied in the Sichuan Province [13,26,35,40] and assumed in Qinghai [30]; the latter was found significant in the eastern fringe of the Plateau in the Gansu Province [17]. Overgrazing and deforestation are considered major ecological phenomena in western China [49-51]. Both risk factors deserve further research to understand their role in general, and in promoting the transmission of E. multilocularis and consequently advancing AE prevalence, as well as their implications for control options.

In conclusion, echinococcosis was identified as a priority for control and research globally, and in China [4,7,52-54]. Deworming both owned and stray dogs should be a major measure for controlling echinococcosis on the Plateau; treatment of wild definitive hosts should also be considered for AE-endemic areas. Health education activities should be in concert with the local population's education background and local languages in order to help improve behaviors. Further researches are needed to clarify the importance of wild hosts for the AE/CE prevalence, the impact of ecologic changes (overgrazing and deforestation) on the $\mathrm{AE}$ prevalence, and risk factors in Tibet.

\section{Additional file}

Additional file 1: Multilingual abstracts in the six official working languages of the United Nations.

Competing interests

The authors declare that they have no competing interests.

\section{Authors' contributions}

WQ, WW, ZB and LW conceived the review concept, carried out the literature search, developed the structure for the manuscript, and drafted the paper. Other authors participated to organize the draft sections, co-wrote sections of the draft, and edited the overall manuscript. All authors read and approved the final version of the manuscript before its submission to IDP.

\section{Acknowledgements}

We thank Prof. Zhou Xiao-Nong, the Director General of the Institute of Parasitic Diseases of China CDC, for his critical comments on the manuscript and for editorial assistance in drafting the manuscript.

\section{Author details}

${ }^{1}$ Sichuan Provincial Center for Diseases Control and Prevention, Chengdu, Sichuan, China. ${ }^{2}$ Ganzi Prefecture Center for Diseases Control and Prevention, Kangding, Sichuan, China. ${ }^{3}$ Institute of Parasitic Diseases, China Center for Diseases Control and Prevention, Shanghai, China. ${ }^{4} \mathrm{WHO}$ Collaborating Center for Prevention and Treatment of Human Echinococcosis, University Hospital and University of Franche-Comté, 25030 Besançon, France. ${ }^{5}$ Department of Chrono-Environment, UMR UFC/CNRS 6249 aff. INRA, University of Franche-Comté, Besançon, France. ${ }^{6}$ Cestode Zoonoses Research Group, Bioscience Research Institute and School of Environment and Life Sciences, University of Salford, Great Manchester M5 4WT, UK.

Received: 8 September 2013 Accepted: 22 January 2014 Published: 29 January 2014

\section{References}

1. Eckert J, Ammann RW: Clinical diagnosis and treatment of echinococcosis in humans. In Echinococcus and hydatid disease. Edited by Lymbery AJ, Thompson RCA. Wallingford, Oxon: CAB International; 1995:411-463.

2. Ammann RW, Eckert J: Cestodes: Echinococcus. Gastroenterol. Clin. N. Am. 1996, 25:655-689.

3. Craig PS, Deshan L, Zhaoxun D: Hydatid disease in China. Parasitol Today 1991, 7(2):46-50

4. World Health Organization: Working to overcome the global impact of neglected tropical diseases, First WHO report on neglected tropical diseases. Geneva; 2010:107-112.

5. Budke CM, Deplazes P, Torgerson PR: Global socioeconomic impact of cystic echinococcosis. Emerging infectious diseases 2006, 12(2):296.

6. Torgerson PR, Keller K, Magnotta M, Ragland N: The Global Burden of Alveolar Echinococcosis. PLoS Negl Trop Dis 2010, 4(6):e722.

7. $\mathrm{MOH}$ (Ministry of Health, China): Report on the national survey of current status of major human parasitic diseases in China. Beijing: People's health publishing house; 2007:3-257.

8. Zhang YL, Zhang W, Bai WQ, Zheng D: Analysis of statistics of Qinghai-Tibet Plateau-a population perspective. Progress in Geography 2005, 24(1):11-20

9. Thompson RCA, McManus DP: Aetiology: parasites and life-cycles. In WHO/OIE manual on echinococcosis in humans and animals. Edited by Eckert J, Gemmell MA, Meslin FX, Pawlowski ZS. Paris: France; 2001:1-16.

10. Craig PS, Giraudoux P, Shi D, Bartholomot B, Barnish G, Delattre P, Quere JP, Harraga S, Bao G, Wang Y, Lu FJ, Ito A, Vuitton DA: An epidemiological and ecological study of human alveolar echinococcosis transmission in south Gansu. China. Acta Trop 2000, 77(2):167-177.

11. Wang H, Ma SM, Cao DP, Zhao HL: An epidemiology survey on human hydatidosis in Southern Qinghai Plateau. Chin J Parasit Dis Con 2000, 13(1):37-40 
12. Schantz PM, Wang H, Qiu J, Liu FJ, Saito E, Emshoff A, Ito A, Roberts JM, Delker C: Echinococcosis on the Tibetan Plateau: prevalence and risk factors for cystic and alveolar echinococcosis in Tibetan populations in Qinghai Province, China. Parasitol 2003, 127(I):109-120.

13. Wang Q, Vuitton DA, Xiao YF, Budke CM, Campos-Ponce M, Schantz PM, Raoul F, Yang W, Craig PS, Giraudoux P: Pasture types and Echinococcus multilocularis, Tibetan communities. Emerg Infect Dis 2006, 12:1008-1009.

14. Pawłowski ZS, Eckert J, Vuitton DA, Ammann RW, et al: Echinococcosis in humans: clinical aspects, diagnosis and treatment. In WHO/OIE manual on echinococcosis in humans and animals. Edited by Eckert J, Gemmell MA, Meslin FX, Pawlowski ZS. Paris: France; 2001:20-68.

15. Gong XH, Ci WZZ, Ze YG, Lu HZ, Pan XZ, Wen XH: Analysis of 709 cases of cystic echinococcosis in Tibet Autonomous region. Chin J Parasitol Parasit Dis 2001, 19(2):128.

16. Wang Q, Qiu JM, Schantz PM, He JG, Ito A, Liu FJ: Risk factors for development of human hydatidosis among people whose family raising livestock in Western Sichuan Province, China. Chin J Parasit Dis Parasitol 2001, 19:289-293.

17. Giraudoux P, Craig PS, Delattre P, Bao G, Bartholomot B, Harraga S, Quéré JP, Raoul F, Wang Y, Shi D, Vuitton DA: Interactions between landscape changes and host communities can regulate Echinococcus multilocularis transmission. Parasitology 2003, 127(I):121-31.

18. He DL, Wu XH, Liu BR, Liu HQ, Ma X, Liu PY, Liu YF, Tang XY, Wang H: An epidemiological survey on hydatid diseases in Yushu County. Qinghai Province. J Trop Dis Parasitol 2003, 1(1):24-26.

19. Qi $Y Z$, Jia $X M$, Jin ZY, Zhang $Y H$, Zhang ZP: epidemiology investigation on echinococcosis in Tianzhu Tibetan Autonomous County, Gansu Province. End Dis Bull 2003, 18(2):51-53.

20. SHI DZ LIWK, BAO GS: Prevalence of alveolar echinococcosis in Gansu Province and human behavior risk factors. [J]. China Public Health 2003, 19(8):973-974

21. Shi DZ, Zhao YM, Guo ZH, Bao GS, Li FR, Chen G, Li WK, Wen JW, Craig PS: Prevalence and risk factor analysis of alveolar echinococcosis in Dingxi prefecture of Gansu Province. Chin J Zoonoses 2004, 20(9):815-817.

22. Pang YK: Analysis on epidemic status of echinococcosis in Yunnan Province. Chin J Parasit Dis Con 2004, 17(4):238-240.

23. Wang $\mathrm{H}$ : Analysis on risk factors of human hydatidosis in Qinghai Province. Chin J Parasit Dis Con 2004, 17(4):214-216.

24. Dong Y, Luo TP, Du ZW, Gan ZM, Fang W: Analysis of prevalence status of hydatid disease in Yunnan Province and affecting factors. Chin Trop Med 2006, 6(10):1773-1774

25. Han XM, Wang H, Ma X: Endemic situation of alveolar and cystic echinococcosis in Banma County of Qinghai Province. Chinese Journal of Zoonoses 2006, 22(2):189-190

26. Wang Q, Vuitton DA, Qiu JM, Giraudoux P, Xiao YF, Schantz PM, Raoul F, Li TY, Yang W, Craig PS: Fenced pasture: a possible risk factor for human alveolar echinococcosis in Tibetan pastoralist communities of Sichuan. China. Acta Trop 2004, 90(3):285-293.

27. Li TY, Qiu JM, Yang W, Craig PS, Chen XW, Xiao N, Ito A, Giraudoux P, Mamuti W, Yu W, Schantz PM: Echinococcosis in Tibetan Populations, Western Sichuan Province, China. Emerg Infect Dis 2005, 11(12):1866-1873.

28. Wang $H$, ZHANG JX: Epidemiologic survey and analysis on echinococcosis in humans and animals from 1995 to 2005 in Qinghai province. Chinese Journal of Zoonoses 2006, 22(12):1129-1134.

29. Yu W, Li DY, Chen XW, Yang W, Qiu JM: Epidemiological Survey on Human Echinococcosis in Four Counties of Gaizi Tibetan Autonomous Prefecture, Sichuan. Parasitoses and Infectious Diseases 2005, 3(4):170-172

30. Han XM, Wang H, Cai HX, Ma X, Liu YF, Wei BH, Ito A, Craig PS: Epidemiological survey on echinococcosis in Darlag county of Qinghai Province. Chin J Parasitol Parasit Dis 2009, 27(1):23-26.

31. Zhao YM, Jing T, Ma SM, Shi DZ, Liang Z, Zhang XX, Zhong SG: A study of the prevalence of human echinococcosis in Maqu and Luqu counties and Gannan Tibetan Autonomous Prefecture. China. J Pathog Biol 2010, 5(1):42-44.

32. Li QY, Yan JW, Guo JB, Pu Q: Report of 47 cases of hepatic cystic echinococcosis in Tibet. J Clini Hepatol 2011, 27(7):756-757.

33. Bai $Y$, Cheng $N$, Jiang $C$, Wang $Q$, Cao D: Survey on cystic echinococcosis in Tibetans. West China. Acta Trop 2002, 82(3):381-385.

34. Budke CM, Campos-Ponce M, Wang Q, Torgerson PR: A canine purgation study and risk factor analysis for echinococcosis in a high endemic region of the Tibetan plateau. Vet Parasitol 2005, 127:43-49.
35. Wang Q, Raoul F, Budke C, Craig PS, Xiao YF, Vuitton DA, Campos-Ponce M, Qiu DC, Pleydell D, Giraudoux P: Grass height and transmission ecology of Echinococcus multilocularis in Tibetan communities. China. Chin Med J 2010, 123(1):61-67.

36. Wang Q, Qiu J, Yang W, Schantz PM, Raoul F, Craig PS, Giraudoux P, Vuitton DA: Socioeconomic and behavior risk factors of human alveolar echinococcosis in Tibetan communities in Sichuan, People's Republic of China [J]. The American journal of tropical medicine and hygiene 2006, 74(5):856-862

37. Giraudoux P, Pleydell D, Raoul F, et al: Transmission ecology of Echinococcus multilocularis: What are the ranges of parasite stability among various host communities in China?[J]. Parasitology international 2006, 55:S237-S246.

38. Wang H, Chai JJ, Liu FJ, Jiang L, Jiao W, Ma SM, Cao DP, Wu XH, He DL: A study on ecological-epidemiology of two hydatid diseases in Qinghai. Chin J Parasit. Dis Con 2002, 15(5):284-287.

39. Qiu JM, Liu FJ, Schantz PM, Ito A, Delker C, He JG, Zhang Y, Chen XW: Epidemiological study on human hydatidosis in Tibetan region of Western Sichuan. Chin J Zoonoses 2000, 16:77-80.

40. Wang Q, Xiao YF, Vuitton DA, Schantz PM, Raoul F, Budke C, Campos-Ponce M, Craig PS, Giraudoux P: Impact of overgrazing on the transmission of Echinococcus multilocularis in Tibetan pastoral communities of Sichuan Province, China. Chin Med J 2007, 120:237-242.

41. He JG, Qiu JM, Liu FJ, Chen XW, Liu D, Chen W, Liu DL, Chen WD, Zhang Y, Schantz P: Epidemiological survey on hydatidosis in Tibetan region of western Sichuan: II. Infection situation among domestic and wild animals. Chin J Zool 2000, 16:62-5.

42. Vuitton DA, Zhou H, Bresson-Hadni S, Wang Q, Piarroux M, Raoul F, Giraudoux P: Epidemiology of alveolar echinococcosis with particular reference to China and Europe [J]. Parasitology 2003, 127(I):87-108.

43. Craig P: Echinococcus multilocularis [J]. Curr Opin Infect Dis 2003, 16(5):437-444.

44. Xinhuanews: Early snow storm and low temperature, gazelles experience hardship this winter; 2008. Accessed Aug. 8, 2012. www.sc.xinhuanet.com/ content/2008-11/20/content_14971000.htm. Accessed on Jan. 3, 2013.

45. Zhang JL, He W: Sanjiangyuan wildlife populations increased. XinhuaNet; 2011. http://www.qh.xinhuanet.com/2011-08/18/content_23493367.htm. Accessed on Jan. 3, 2013

46. Zhang JX, Wang H: Epidemiological Survey on Echinococcus infection in animals in Qinghai Province. Chin J Parasitol Parasit Dis 2007, 25(4):350-352.

47. Yu WJ, Huang L, Yao YQ, Wang XQ, Ma L, Ze LRL, Li YQ, Huang Y, Yi DY, Wang Q: Study on the seasonal infection pattern of dogs by echinococcus granulosus in cystic echinococcosis endemic area, western Sichuan Province. China. J Pathog Biol 2012, 7(4):280-281,251.

48. Rosner B: Fundamentals of biostatistics. 5th edition. New York, NY: Duxbury Press; 2000.

49. China Ministry of Agriculture: China overgrazed pastoral grassland leads to serious environment deterioration; 2011. http://www.gov.cn/jrzg/2011-07/11/ content_1903875.htm. Accessed on December 27, 2013.

50. A Bulletin of Status Quo of Desertification and Sandification in China: State Forestry Administration, China; 2011. http://www.greentimes.com/green/ econo/hzgg/ggqs/content/2011-01/05/content_114232.htm. Accessed on December 27, 2013.

51. Wang SH: The Probe on the desertification of the western regions in China. Journal of Northwest University 2005, 35(4):15-21.

52. Zhou XN: Prioritizing research for "One health - One world". Infectious Diseases of Poverty 2012, 1:1.

53. Xiao N, Yao JW, Ding W, Giraudoux P, Craig PS, Ito A: Priorities for research and control of cestode zoonoses in Asia. Infectious Diseases of Poverty 2013, 2:16.

54. Zheng Q, Vanderslott S, Jiang B, Xu LL, Liu CS, Huo LL, Duan LP, Wu NB, Li SZ, Xia ZG, Wu WP, Hu W, Zhang HB: Research gaps for three main tropical diseases in the People's Republic of China. Infectious Diseases of Poverty 2013, 2:15

doi:10.1186/2049-9957-3-3

Cite this article as: Wang et al:: Review of risk factors for human echinococcosis prevalence on the Qinghai-Tibet Plateau, China: a prospective for control options. Infectious Diseases of Poverty 2014 3:3. 